\title{
Galveston Orientation \& Amnesia Test (GOAT) Score to Assess Degree of Severity in Mild
} Brain Injury

\author{
Zieky Yoansyah $^{1}$, Sahat Edison Sitorus ${ }^{1 *}$ \\ ${ }^{1}$ Department of Surgery, Faculty of Medicine, Universitas Sriwijaya \\ *Corresponding Author Email: edisonsitorus@ gmail.com
}

\begin{abstract}
Introduction. Most of the minor brain injuries will heal as usual, but around 10-15\% even 58\% experience a continuous or chronic disorder known as post-traumatic syndrome. Post traumatic syndrome has manifested in the first 7 days where the quality of life of patients has decreased significantly. This study aimed to assess post traumatic amnesia in minor traumatic brain injuries in Emergency, Inpatient, and Outpatient RSUP. Moh. Hoesin Palembang using GOAT to determine the classification of minor brain injuries based on post traumatic amnesia and determine the prognosis of mild traumatic brain injury according to the presence or absence of post-traumatic syndrome.

Methods. This research is an analytic survey with cross sectional approach. The subjects of this study were patients who were admitted and treated at the Emergency Department, Inpatient Installation, and Outpatient Installation (Polyclinic) at the RSUP dr. Mohammad Hoesin Palembang with mild traumatic brain injury and met the inclusion criteria. Inclusion criteria were patients who present with mild brain injury (GCS EMV score 13-15), age $\geq 15$ years, the time of the event lasts longer $\leq 24$ hours, agreeing and signing informed consent

Results. Amnesia assessment uses the GOAT (Galveston Orientation and Amnesia Test) which is divided into three categories, namely PTA free if results $>75$, and still in amnesia period if results $<66$ and 66-75 are doubtful. Based on GOAT assessment the number of Amnesia respondents was 23 people $(42.6 \%)$ with an average GOAT score or score of 67.6 .
\end{abstract}




\section{STS SRIWIJAYA JOURNAB OFEURGERY}

Conclusion. There is a significant relationship between the incidence of amnesia and posttraumatic syndrome using the GOAT Score assessment.

Keywords. galveston orientation amnesia test, degree of severity, mild brain injury

\section{Introduction}

Currently traumatic brain injury which is defined as impaired brain function due to temporary or permanent brain damage due to external energy affecting the head directly or indirectly, is a major public health problem because it is one of the biggest causes of disability throughout the world. The incidence of traumatic brain injury is estimated at 558 per 100,000 population annually 1 and minor traumatic brain injury is estimated to be around $75 \%$ of all traumatic brain injuries. ${ }^{2-4}$

Most of the minor brain injuries will heal as usual, but around 10-15\% even 58\% experience a continuous or chronic disorder known as post-traumatic syndrome. ${ }^{3-5}$ Post traumatic syndrome has manifested in the first 7 days where the quality of life of patients according to the Lipp and Ocha assessment has decreased significantly. ${ }^{6-8}$ Estimated cost to diagnose and treat mild traumatic brain injury without and with complications reaches 17 billion US dollar does not include losses due to decreased performance and productivity. ${ }^{9-10}$

Limitation of mild traumatic brain injury varies, both by the American Congress of Rehabilitation Medicine (ACRM), the Center of Disease Control or WHO, which is based on the Glasgow Coma scale of 13-15 at initial examination, history of loss of consciousness under 30 minutes and amnesia post-traumatic or post-traumatic amnesia under 24 hours after trauma. Among the presentations on the Glasgow Coma Scale, the duration of loss of consciousness, as well as the duration of post-traumatic amnesia in mild traumatic brain injury to determine the classification of mild, moderate, severe brain injury apparently post traumatic amnesia (PTA) have a value in determining the severity of brain injury and the determination of prognostic significance because it can only be measured when full awareness and the Glasgow Coma Scale are maximum i.e. GCS score of 15 which is determined by self orientation, place and time. ${ }^{12}$ PTA is defined as the time lapse from the last memory before the trauma until the return of memory and states it, 
with a normal orientation, therefore PTA can be said to include periods of loss of consciousness, confusion or disorientation or other disturbance of consciousness. ${ }^{13-15}$

There are various ways of measuring PTA, each of which has advantages and disadvantages in terms of ease of implementation and desired results. One of them is the Galveston Orientation and Amnesia Test abbreviated as GOAT, which was developed on the basis of orientation or self-introduction, place, and time. ${ }^{16}$ From the results of tests that are numeric in nature totaling 100, can be classified into three categories, namely PTA free if results $>75$, and is still in the amnesia period if results $<66$ and 66-75 are doubtful.

PTA assessment which is a diagnostic, prognostic determination for patients with mild brain injury has not yet become a management standard. The use of GOAT on a regular basis both in the ED, Inpatient Installation and Outpatient Installation has not been implemented in the Moh. Hoesin General Hospital Palembang.

This study aimed to assess PTA in minor traumatic brain injuries in Emergency, Inpatient, and Outpatient RSUP. Moh. Hoesin Palembang using GOAT to determine the classification of minor brain injuries based on PTA and determine the prognosis of mild traumatic brain injury according to the presence or absence of post-traumatic syndrome.

\section{Methods}

This research is an analytic survey with cross sectional approach. The subjects of this study were patients who were admitted and treated at the Emergency Department, Inpatient Installation, and Outpatient Installation (Polyclinic) at the RSUP dr. Mohammad Hoesin Palembang with mild traumatic brain injury and met the inclusion criteria. Inclusion criteria were patients who present with mild brain injury (GCS EMV score 13-15), age $\geq 15$ years, the time of the event lasts longer $\leq 24$ hours, agreeing and signing informed consent. Exclusion criteria were patients with moderate and severe brain injuries and other severe accompanying injuries (multiple trauma) with haemodynamic and respiratory disorders, patients with alcohol or drug addiction, patients with aphasia.

Patients with mild traumatic brain injury are sufferers of head injuries caused by head trauma with a GCS scale value of 13-15 according to ACRM criteria. Post-traumatic amnesia is the time between the moment of trauma to the head and the return of normal memory function. 


\section{SSSS SRIWIJAYA JOURNABOFEURGERY}

GOAT is a post traumatic amnesia measurement scale that is, free of PTA if $>75$; Doubts 66-75 and amnesia $<65$.

Data on age, sex, trauma mechanism and GOAT scores were recorded. The univariate data that have been collected are presented in the form of distribution, frequency and narrative tables. Bivariate tests were then performed using the chi square test, with $\mathrm{P}<0.05$.

\section{Results}

Amnesia assessment uses the GOAT (Galveston Orientation and Amnesia Test) which is divided into three categories, namely PTA free if results $>75$, and still in amnesia period if results $<66$ and 66-75 are doubtful. Based on GOAT assessment the number of Amnesia respondents was 23 people $(42.6 \%)$ with an average GOAT score or score of 67.6.

Post traumatic syndrome (PTS) is assessed based on patient complaints with the presence of signs and symptoms of headache, vertigo or dizziness, nervousness, irritability, impaired concentration, memory loss, easy to feel tired, difficulty sleeping, sexual dysfunction, and loss of tolerance to alcohol. In this study the signs and symptoms found were headache, vertigo, impaired concentration, fatigue, and difficulty sleeping. A total of 29 people (53.7\%) experienced posttraumatic syndrome.

The relationship between the incidence of amnesia and post-traumatic syndrome is tabulated in Table 1, data analysis using the Pearson Chi-Square test showed $\mathrm{p}=0.010$, statistically significant ( $\mathrm{p}$ value $<0.05)$.

Table 1. Crosstabulation Amnesia with PTS

\begin{tabular}{|l|l|c|c|c|}
\hline \multicolumn{2}{|c|}{} & \multicolumn{2}{|c|}{ Post traumatic syndrome } & \multirow{2}{*}{} \\
\cline { 3 - 5 } \multicolumn{2}{|c|}{} & Positive & Negative & \multicolumn{1}{|c|}{} \\
\hline \multirow{3}{*}{$\begin{array}{l}\text { Amnesia } \\
\text { Category }\end{array}$} & \multirow{2}{*}{ No amnesia } & 17 & 6 & 23 \\
\cline { 3 - 5 } & & $(73,9 \%)$ & $(26,1 \%)$ & $(100 \%)$ \\
\cline { 3 - 5 } & $(38,7 \%)$ & $(61,3 \%)$ & $(100 \%)$ \\
\hline & 29 & 25 & 54 \\
\cline { 3 - 5 } & & $(53,7 \%)$ & $(46,3 \%)$ & $(100 \%)$ \\
\hline
\end{tabular}




\section{STS SRIWIJAYAJOURNAB OFEURGERY}

\section{Discussion}

This study is an analytic survey with cross sectional study to find the ratio of PTA prevalence in mild traumatic brain injury and the relationship of various patient factors namely gender, age, education, occupation and trauma mechanism to amnesia scores. In this study, 54 patients with mild traumatic brain injury according to the ACRM (The American Congress of Rehabilitation Medicine) criteria who came in the emergency department, inpatient and outpatient Dr. Moh. Hoesin General Hospital Palembang during the period January 2018 - February 2018. Patient data were taken in a sequential or consecutive sampling period of 2 months (January to February 2018). Patient characteristics are divided based on age, sex, occupation and level of education as well as the mechanism of trauma causing traumatic brain injury. The mean age of the study subjects was 35.63 years. The highest age is the subject of 80 years and the lowest is 15 years. The highest number of sufferers at the age of 15-50 years old is as many as 45 people (83.3\%) which can be categorized as young adults or productive ages. Bondanelli et al in 2005 in traumatic brain injury, the highest incidence in the age group 15-24 years or 75 years, while in children the peak incidence is at the age of less than 5 years.

Incidence rates for men are twice as frequent as women with the highest ratio in adolescents and young adults, and range from 1.2: 1 to 4.4: 1 in different populations. Male sufferers numbered 42 people $(77.8 \%)$, while female sex numbered 12 people $(22.2 \%)$. The results of the study are in accordance with the literature, which found more men with a ratio of approximately 2: 1. ${ }^{16-20}$ The level of secondary education had the most traumatic brain injury with an incidence of 30 people $(55.6 \%)$ and in higher education by 2 people ( $3.7 \%$ ). In the distribution of types of work, the professions that suffered the most minor traumatic brain injury were entrepreneurs as many as 13 people $(24.1 \%)$ and at least one driver (1.9\%). Frequency distribution based on the type of trauma mechanism, from 54 study subjects, the most common cause of minor traumatic brain injury was traffic accidents of 42 people $(77.8 \%)$ while 12 non-traffic accidents (22.2\%). In accordance with many literature which mentions the most is traffic accidents, especially motorized. In the study between Amnesia and the incidence of post-traumatic syndrome (PTS), five parameters and signs of symptoms arising from Mild Traumatic Brain Injury and a significant relationship were found. 


\section{SSS SRIWIJAYA JOURNAL OFSURGERY}

\section{Conclusion}

There is a significant relationship between the incidence of amnesia and post-traumatic syndrome using the GOAT Score assessment.

\section{References}

1. Cynthia L. Leibson, Allen W. Brown, Jeanine E. Ransom, Nancy N. Diehl, Patricia K. Perkins, Jay Mandrekar, andJames F. Malec' Incidence of Traumatic Brain Injury Across the Full Disease Spectrum: A Population-Based Medical Record Review Study, Epidemiology. 2011 Nov; 22(6): 836-844.

2. Centers for diseases control and preventions, CDC's Report to Congress on Traumatic Brain Injury Epidemiology and Rehabilitation, 2016

3. Anderson-Barnes, Victoria C.; Weeks, Sharon R.; Tsao, Jack W., Mild traumatic brain injury update, Lifelong Learning in Neurology: December 2010 - Volume 16 - Issue 6, $\underline{\text { Traumatic Brain Injury - p 17-26 }}$

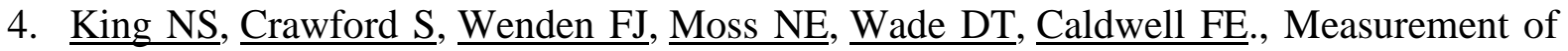
post-traumatic amnesia:how reliable is it?. Journal of Neurology, Neurosurgery, and Psychiatry 1997;62:38-42

5. Lew, Henry L. MD, PhD; Lin, Pei-Hsin MD; Fuh, Jong-Ling MD; Wang, Shuu-Jiun MD; Clark, David J. MD, PhD; Walker, William C. MD, Characteristics and Treatment of Headache After Traumatic Brain Injury: A Focused Review, American Journal of Physical Medicine \& Rehabilitation: July 2006 - Volume 85 - Issue 7 - p 619-627

6. S. Faux, FAFRM (RACP) FFPMANZCAJ. Sheedy, BApp Sc (Physio), B.Psych Grad Dip (Research), A Prospective Controlled Study in the Prevalence of Posttraumatic Headache Following Mild Traumatic Brain Injury, Pain Medicine, Volume 9, Issue 8, 1 November 2008, Pages 1001-1011 


\section{SSS SRIWIJAYA JOURNABOPSURGERУ}

7. Nampiaparampil DE, Prevalence of chronic pain after traumatic brain injury: a systematic review.JAMA. 2008 Aug 13;300(6):711-9.

8. Hugo André de Lima Martins, Bianca Bastos Mazullo Martins, Valdenilson Ribeiro Ribas, Silvya Nery Bernardino, Daniella Araújo de Oliveira, Louana Cassiano Silva, Everton Botelho Sougey, Marcelo Moraes Valença, Life quality, depression and anxiety symptoms in chronic post-traumatic headache after mild brain injury, Dement. neuropsychol. vol.6 no.1 São Paulo Jan./Mar. 2012

9. Vincent AS, Roebuck-Spencer TM, Cernich A. Cognitive changes and dementia risk after traumatic brain injury: implications for aging military personnel. Alzheimers Dement. 2014 Jun;10(3 Suppl):S174-87.

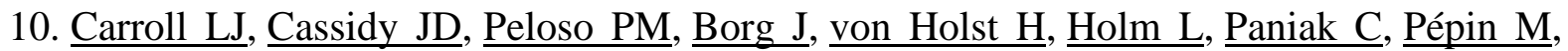
Prognosis for mild traumatic brain injury: results of the WHO Collaborating Centre Task Force on Mild Traumatic Brain Injury. J Rehabil Med. 2004 Feb;(43 Suppl):84-105.

11. Bob Roozenbeek, Andrew I. R. Maas, David K. Menon, Changing patterns in the epidemiology of traumatic brain injury. 2013, Nat. Rev. Neurol. 9, 231-236

12. Russell WR, Nathan PW. Traumatic amnesia. Brain. 1946 Dec;69(4):280-300.

13. Taylor HG, Drotar D, Wade S, et al. Recovery from traumatic brain injury in children: the importance of the family. In: Broman S, Michel ME, eds.Traumatic head injury in children. New York: Oxford University Press, 1995:188-218.

14. Ronald M. Ruff, Paul Jurica In search of a unified definition for mild traumatic brain injury, Brain 1999, Vol. 13 issue 12 p. 943-952 


\section{STS SRIWIJAYAJOURNAB OFEURGERY}

15. Levin HS, Grossman RG, Rose JE, Teasdale G. Longterm neuropsychological outcome of closed head injury. J Neurosurg 1979;50:412-22.

16. Brown AW, Malec JF, McClelland RL, Diehl NN, Englander J, Cifu DX. Clinical elements that predict outcome after traumatic brain injury: a prospective multicenter recursive partitioning (decision-tree) analysis. J Neurotrauma. 2005 Oct;22(10):1040-51.

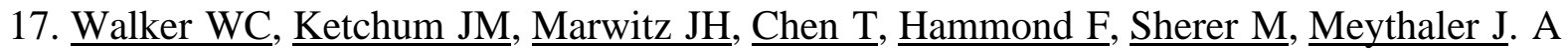
multicentre study on the clinical utility of post-traumatic amnesia duration in predicting global outcome after moderate-severe traumatic brain injury. $\underline{\mathrm{J} \text { Neurol Neurosurg }}$ Psychiatry. 2010 Jan;81(1):87-9.

18. W. Ritchie Russell, M.D., D.Sc., F.R.C.P.; Aaron Smith, Ph.D. Post-Traumatic Amnesia in Closed Head Injury. Arch Neurol. 1961;5(1):4-17

19. B Jennett, J Snoek, M R Bond, N Brooks, Disability after severe head injury: observations on the use of the Glasgow Outcome Scale.Journal of neurology, neurosurgery, and psychiatry, 1981, Vol. 44, Issue 4, 285-293.

20. Laurence A.G. Marshman, David Jakabek, Maria Hennessy, Frances Quirk, Eric P. Guazzo. Post-traumatic amnesia . Journal of Clinical Neuroscience 20 (2013) 1475-1481 